\title{
Identidade e memória nos documentários da TV OVO: a ressignificação local em projetos de comunicação comunitária
}

\author{
Neli Fabiane Mombelli \& Cássio dos Santos Tomaim*
}

Resumo: Este artigo estuda a ressiginificação da memória e a construção da identidade local ao analisar documentários da TV OVO sobre bairros de Santa Maria/RS. O pressuposto teórico parte do documentário enquanto "lugar de memória" e avalia a existência de uma perspectiva de comunicação contra-hegemônica a partir da análise fílmica.

Palavras-chave: memória; identidade; documentário; comunicação comunitária.

Resumen: Este artículo estudia la resignificación de la memoria y la construcción de la identidad local al analizar documentales de TV OVO sobre barrios de Santa Maria/RS. El presupuesto teórico parte del documental como un "lugar de memoria"y evalúa la existencia de una perspectiva de comunicación contrahegemónica a partir del análisis fílmico.

Palabras clave: memoria; identidad; documental; comunicación comunitaria.

\begin{abstract}
This article studies the memory reframed and the construction of local identity through the analysis of TV OVO documentaries about neighborhoods on the city of Santa Maria/RS. The theoretical purpose is the documentary as a "place of memory" and the existence of a communication counterhegemonic perspective by the film analysis.

Keywords: memory; identity; documentary; community communication.

Résumé: Cet article étudie la ressignification de la mémoire et la construction d'une identité locale en analysant des documentaires de TV OVO sur des quartiers de Santa Maria/RS. L'hypothèse théorique a comme point de départ le documentaire en tant que « lieu de mémoire » et examine l'existence d'une perspective contre-hégémonique à partir de l'analyse du film.

Mots-clés: mémoire; identité; documentaire; communication de la Communauté.
\end{abstract}

\footnotetext{
* Neli Fabiane Mombelli: Doutoranda. Universidade Federal de Santa Maria UFSM, Departamento de Ciências da Comunicação, Programa de Pós-Graduação em Comunicação. 97105-900, Santa Maria, Brasil. E-mail: nelifabiane@gmail.com Cássio dos Santos Tomaim: Universidade Federal de Santa Maria - UFSM, Departamento de Ciências da Comunicação, Programa de Pós-Graduação em Comunicação. 97105-900, Santa Maria, Brasil. E-mail: tomaim78@gmail.com
} 


\section{Introdução}

Neste artigo, ${ }^{1}$ buscamos compreender como a memória e a identidade de uma cidade são ressignificadas em documentários que abordam a construção simbólica e o imaginário social desse lugar a partir da representação de bairros eleitos patrimônios culturais. A preocupação com a memória, que compreende lembranças e esquecimentos, surge com a modernidade. A rápida modernização da América Latina e o culto do tempo presente acabaram por distanciar o hoje do ontem, e nesse processo muitos dos rastros do passado que dão sustentação às identidades, se apagaram com os respingos do desenvolvimento.

Assim, a fórmula encontrada para ligar o presente ao passado e resgatar as origens das identidades é a criação de "lugares de memória". Como afirma Pierre Nora (1993: 7), esses lugares são criados porque não existem mais meios de memória. Assim, a memória assume formas, torna-se tangível, material, deixando de transitar entre lembranças e esquecimentos que são a sua essência. Os "lugares de memória" possuem no seu devir uma vontade de memória, constituindo-se em objetos ou convenções que mantêm viva e simbolizada, em qualquer detalhe, a inconstância das lembranças que vão e vêm em nossa mente. E nesse ínterim é que se constituem os laços de pertencimento e as identidades.

São esses aspectos que analisamos neste artigo, tendo em vista que os dois documentários selecionados retratam o patrimônio cultural de Santa Maria, cidade ao centro do Estado do Rio Grande do Sul, no extremo Sul do Brasil, que tem como fio condutor da narrativa audiovisual a construção de uma memória santa-mariense.

Os documentários são produzidos pela TV OVO, um projeto de comunicação comunitária, constituído juridicamente em uma associação sem fins lucrativos, que iniciou suas atividades em 1996, na Vila Caramelo, zona oeste de Santa Maria. No início, era uma oficina de audiovisual para os adolescentes do bairro periférico mas, em 1997, foi institucionalizada pelos próprios jovens participantes, que se tornaram monitores das oficinas do ano seguinte. A cada nova turma, o grupo anterior era responsável por repassar os conhecimentos para quem estava chegando. A TV OVO se caracteriza como um meio de comunicação comunitário e que, simultaneamente, visa à capacitação profissional de jovens em situação de exclusão social e promove a democratização do direito social à cultura, com foco no audiovisual.

1. Este artigo é resultado da dissertação de mestrado intitulada Santa Maria projetada: memória e identidade nos documentários da TV OVO defendida no programa de Pós-Graduação em Comunicação da Universidade Federal de Santa Maria, sob orientação de Cássio dos Santos Tomaim. 
Dentro dessa perspectiva, um dos projetos desenvolvidos por ela é o Por onde passa a memória da cidade, que conta com recursos públicos advindos da lei de incentivo à cultura de Santa Maria (LIC/SM). É ele que abarca os dois documentários ${ }^{2}$ que analisamos. Os documentários Qu4tro Mistérios do Rosário $^{3}$ (Marcos Borba, 2012) e Trilhos do Itararé ${ }^{4}$ (Marcos Borba, 2012) abordam dois bairros hoje adjacentes ao centro, mas que em meados do século passado eram considerados periféricos devido às proporções de Santa Maria e, também, no caso do bairro Nossa Senhora do Rosário, por ser um local habitado por uma população desfavorecida economicamente. Os filmes contam a história de formação e desenvolvimento desses bairros, sendo o Itararé o bairro dos ferroviários e o Nossa Senhora do Rosário o bairro negro da cidade, que hoje se transformou em um bairro universitário.

A proposta de eleger a TV OVO e seus documentários como objeto de estudo, isto é, um objeto de características locais é porque em função das políticas culturais, principalmente na esfera nacional, que têm fomentado a produção audiovisual no país, grupos pequenos e desconhecidos estão tendo a oportunidade de registrarem suas realidades. Neste tocante, analisar o que a TV OVO, que se enquadra neste perfil, está produzindo e como ela vê e retrata o contexto de sua cidade, abre perspectivas para outras pesquisas seguirem nesta linha e pensarem como outros grupos, em outros locais, têm se apropriado do fazer documentário.

Ainda, o artigo traz contribuições para os estudos de Comunicação, Cinema e História, tendo como foco o audiovisual e sua relação com a memória, a identidade, o patrimônio cultural e a comunicação comunitária. Além disso, lançamos o olhar para produções que são, de certa forma, marginalizadas, que têm o circuito exibidor um tanto restrito, voltado mais para cineclubes, itinerâncias, festivais e internet, além de contar com baixo orçamento para realizar suas produções, visto que muitos dos estudos voltados ao documentário geralmente trabalham com documentaristas, produtoras e filmes conhecidos, que

2. Na dissertação trabalhamos com quatro documentários. Para este artigo optamos por deixar os dois primeiros de fora para podermos aprofundar a análise. Assim, não abordaremos o Avenida Progresso (Marcos Borba, 2009) [disponível em https://goo.gl/2d4ivF] que retrata a Avenida Rio Branco a partir dos anos de 1900 e o $1^{a}$ Quadra (Marcos Borba, 2009) [disponível em https://goo.gl/DLuKdR] que aborda a $1^{\text {a }}$ quadra da Rua Dr. Bozzano, hoje Calçadão Salvador Isaia. Ambos recuperam a história de ruas centrais de Santa Maria que sempre tiveram grande importância econômica e cultural no contexto da cidade. O Por onde passa a memória da cidade também abarca quatro mini-documentários biográficos de "personas" de Santa Maria, produzidos em 2011. Estas produções audiovisuais não fizeram parte do nosso objeto por possuírem formato (curta-metragem) e temática (biografia) diferentes dos demais documentários da TV OVO.

3. Disponível em http://goo.gl/s3K5Vv

4. Disponível em http://goo.gl/3PR9Ob 
possuem certa visibilidade no mercado exibidor e que contam com maior aparato tecnológico e recursos financeiros.

\section{Percurso metodológico}

Para estudar a ressiginificação da memória e da identidade nos documentários, usamos como metodologia a análise fílmica, que se baseia na interpretação do produto audiovisual, uma vez que não possui uma fórmula única a ser seguida. Ela analisa a narrativa do filme e a sua composição enquanto produto final, levando em consideração todo um aporte teórico relacionado à linguagem, às teorias do cinema e do filme documentário, além do contexto de produção dos filmes. Para analisar os documentários, trabalhamos a partir de três eixos que definimos como prioritários: as vozes e as maneiras de representar o real; a estética televisiva e os usos e apropriações dos testemunhos; e a memória e a identidade para Santa Maria. A seguir, falaremos brevemente de cada eixo de modo a esclarecer as referências usadas no momento da análise.

As vozes e as maneiras de representar o real referem-se à maneira como qualquer documentário é constituído, isto é, a partir de pontos de vista. A forma como esse ponto de vista é expresso é o que Nichols (2005: 76) chama de a "voz" do documentário. De acordo com o autor, a "voz" fala a partir de como os elementos de imagem e som são dispostos no filme, o que envolve escolhas de linguagem, qual enquadramento será usado, como um plano será composto, quando cortar a sequência, de que forma será montado, se a captação do áudio será direta, se haverá voz-over, trilha, se os acontecimentos seguirão uma sequência lógica ou serão reorganizados, se serão utilizadas imagens em movimento e fotografias de arquivo e, por fim, qual o modo de representação que o documentário irá usar para realizar suas asserções sobre o mundo (Nicholls, 2005).

Um documentário pode ser composto de várias vozes que se manifestam através das entrevistas, das fotografias e imagens de arquivo, das imagens contemporâneas, da voz over, no entanto, ele sempre irá constituir uma voz própria, a partir da conjunção dessas vozes que irão produzir um significado que traduz o ponto de vista, apresentando o argumento ou defendendo uma causa do cineasta. Segundo Nichols, trazer vozes de entrevistados é uma forma de legitimar a voz do filme, uma espécie de estratégia para que a voz do documentário não exerça um tom autoritário. Já os modos de representar o real expressam o modo de ver do diretor do filme e também a forma como o filme se engaja no mundo, uma vez que, para além de oferecer um retrato do mundo reconhecível, como adverte o autor, o documentário também é sinônimo de 
interesses. Ele nunca será uma simples representação do mundo, desprovida de intenções.

São seis os modos de representação elencados por Nichols. ${ }^{5}$ Dentre esses, a TV OVO se utiliza de um deles: o expositivo. Trata-se do mais tradicional. Ele "agrupa fragmentos do mundo histórico numa estrutura mais retórica ou argumentativa do que estética ou poética" (Nichols, 2005: 142), isto é, reconta-se uma história em que a ênfase é voltada para narrativa em si, exposta verbalmente, enquanto que as imagens ficam em segundo plano, num tom mais ilustrativo.

Outra característica muito marcante do modo expositivo é o uso da "montagem de evidência" que, por meio das imagens, irá sustentar o argumento do filme. Para Nichols, a "montagem de evidência" é uma forma de organizar os cortes sem que necessariamente haja uma continuidade, em que tempo e espaço não sejam únicos, mas sim "que se dê a impressão de um argumento único, convincente, sustentado por uma lógica" (Nichols, 2005: 58). No caso dos documentários da TV OVO, esta lógica se dá por meio dos testemunhos dos personagens sociais.

O segundo eixo é composto pela estética televisiva e pelos usos e apropriações dos testemunhos. Embora os documentários aqui analisados sejam considerados próximos da linguagem cinematográfica, já que eles participam de festivais de cinema e são produzidos para serem exibidos em sessões de cineclubes e em sessões itinerantes, eles também se aproximam de uma estética televisiva. Anna Maria Ballogh e Juan Droguett (2008: 42-43) dizem que cinema e televisão, ao serem duas janelas para o mundo contemporâneo, convivem numa inter-relação constante. Para os autores, "o cinema contemporâneo é, em certo sentido, um cinema do esboço, do fragmento" (Ballogh e Droguett, 2008: 45), devido à crescente mescla e indefinição entre estética televisiva e cinematográfica.

Em nosso objeto, essa conjunção se dá na medida em que as obras possuem uma grande dependência de testemunhos na sua narrativa. Esse uso exacerbado configura o que Calabrese (1987) chama de lógica do fragmento. Isto é, para o autor, do ponto de vista discursivo, o fragmento, que faz parte de um inteiro, ao ser fracionado, é como se excluísse o todo do qual pertencia, não contemplando a presença do inteiro (Calabrese, 1987).

Essa estética do fragmento é percebida nos documentários na medida em que eles apresentam diversos recortes de testemunhos que foram extraídos de um todo, de uma entrevista maior. Assim, "o fragmento deixa-se ver pelo ob-

5. Os modos de representação são expositivo, poético, observativo, participativo, reflexivo e performático. 
servador tal como é, e não como um fruto de uma acção do sujeito" (Calabrese, 1987: 88). Segundo o autor, o fragmento não tem uma fronteira delineada, específica, mas é um recorte, uma interrupção, é uma reconstrução.

Além do fragmento, Calabrese fala do detalhe, o que, para ele, é uma estética diferenciada. O detalhe consiste em tornar "perceptível a partir do inteiro e da operação de talho" (Calabrese, 1987: 86). Ou seja, diferentemente do fragmento, que constituirá um novo inteiro, o detalhe ou pormenor é a ação de dar destaque a um elemento, mas que não negligencia o seu inteiro. $\mathrm{O}$ detalhe incorpora as marcas de enunciação. É possível perceber que há um sujeito realizador que faz escolhas e direciona a narrativa. Isso é perceptível em no documentário Qu4tro Mistérios do Rosário, sobre o qual falaremos mais adiante.

Já os testemunhos dividem-se em dois grupos em nossa análise: um se refere às vozes populares, ou seja, às falas de moradores das ruas e bairros de Santa Maria convidados a rememorar suas lembranças sobre os lugares; e o outro tipo se refere às vozes institucionalizadas, isto é, que representam um campo de saber. São aqueles que possuem conhecimento para falar sobre determinado aspecto, como historiadores, arquitetos, etc. Estas vozes, agrupadas em distintas categorizações de testemunhos, são expressas pelo que chamamos de personagens sociais e são articuladas no documentário de diferentes formas para sustentar o ponto de vista da TV OVO.

O último eixo da nossa metodologia é a memória e identidade para Santa Maria. Ao falarmos de Santa Maria e de seu passado, precisamos definir, também, qual é o ponto de vista hegemônico sobre ele para, então, poder inferir que representações os documentários da TV OVO projetam sobre e para a cidade. A partir da leitura da bibliografia sobre Santa Maria, percebemos que os dois livros, um de João Belém (1933) e o outro de Romeu Beltrão (1958), que são referências sobre a história da cidade, relacionam a identidade da cidade às instituições de ensino religiosas, que eram de grande expressão. A partir dos anos de 1980, quando historiadores acadêmicos voltam-se para o passado santa-mariense, há uma mudança neste conceito, e a Santa Maria do final do século XIX passa ser vista como "Cidade Ferroviária". Já no início do século XX, até meados de 1950, o destaque é para a "Cidade do Comércio" e, posterior a isto, com a decadência da ferrovia, como "Cidade Cultura".

Ao partir da ideia do documentário enquanto "lugar de memória" e ao buscar compreender, a partir da leitura dos filmes enquanto práticas comunicacionais de viés comunitário, em que medida estas produções audiovisuais exercem uma perspectiva de comunicação contra-hegemônica, evocando um projeto de 
memória e construindo uma identidade para a cidade de Santa Maria, precisamos situar o lugar da nossa fala em relação ao conceito de contra-hegemonia.

Por hegemonia, consideramos a conceituação do pensador italiano Antonio Gramsci, que na sua obra a entende como um domínio exercido por uma classe sobre outras, envolvendo força e consentimento. Assim, ao compreender a hegemonia enquanto um amplo espectro que envolve não somente a infraestrutura, mas, principalmente, a superestrutura, quando pensamos em identidade e memória entendemos hegemonia como um processo de visão de mundo que é incorporado pela sociedade, em que há negociação e consentimento. A partir disso, tomamos como contra-hegemônico, em nossa pesquisa, um grupo e/ou um movimento e/ou uma prática que vai de encontro a essa forma de incorporação, isto é, que de alguma maneira busca certa autonomia, podendo ser no campo do discurso e/ou das ações. A princípio, é o que se espera de um projeto como o da TV OVO, uma organização social de e para jovens da periferia de Santa Maria que encontra no audiovisual formas e ferramentas que propiciam reflexões sobre a sociedade e que buscam novos caminhos a partir do protagonismo juvenil.

Ainda no âmbito da identidade, trabalhamos a partir da ótica de Castells (2006), que a compreende como uma construção social, marcada fortemente por estruturas de poder. É a partir dessas relações de poder, que envolvem as representações e o imaginário social, que o autor propõe três formas de constituição da identidade. A primeira, chamado por Castells de legitimadora, é aquela mantida pelas instituições que se constituem como dominantes na sociedade como, por exemplo, a escola, a Igreja e o Estado. O autor diz que o objetivo dessa identidade é de aumentar e tornar racional a sua dominação sobre os atores sociais. A segunda, classificada pelo autor como identidade de resistência, é composta por atores que estão em posições desvalorizadas pela sociedade ou de estigma. Ela acaba por criar a sua própria lógica para sobreviver, de modo a se opor à dominação. Já a última, que ele chama de identidade de projeto, se constitui com o auxílio de bens culturais. Isto é, atores sociais se utilizam de algum bem cultural ao seu alcance, o que lhes permite construir uma identidade que redefine o seu lugar na sociedade. As mudanças provocadas pela identidade de projeto podem transformar a estrutura social que envolve os seus atores sociais (Castells, 2006).

Castells (2006) enfatiza que nenhuma identidade constitui uma essência. Elas são dinâmicas ao longo desta sequência, podendo ora ser de resistência, ora ser de projeto ou ainda transformar-se em legitimadora. Essas formas de constituição de identidade, que se referem aos três tipos elencados pelo autor, serão observadas na análise dos dois documentários que compõem nosso 
objeto de estudo, a fim de apontarmos que identidades essas produções audiovisuais da TV OVO constroem para Santa Maria.

\section{A (des)construção de Santa Maria nos documentários}

Neste momento, apresentamos os documentários e uma síntese da análise a partir dos eixos metodológicos estabelecidos, isto é, quanto às vozes e as maneiras de representar o real; a estética televisiva e os usos e apropriações dos testemunhos; e a memória e a identidade para Santa Maria.

O documentário Qu4tro Mistérios do Rosário (Marcos Borba, 2012) conta a história do bairro Nossa Senhora do Rosário a partir de quatro eixos: a Irmandade do Rosário, o clube de negros Treze de Maio, a constituição geográfica do bairro e a comunidade. Os quatro eixos são uma alusão aos quatro mistérios do Rosário, oração católica dedicada à Virgem Maria. O bairro se localiza nas adjacências do centro da cidade, mas era tido como região periférica até meados da década de 1970, devido às proporções do espaço urbano de Santa Maria, que era bem menor na época se comparado com a atualidade.

Os elementos articulados pelo documentário para formar sua voz própria transitam entre o uso de registros in loco, voz-over, letreiros, algumas fotografias antigas, animações de documentos históricos, animações de ilustrações e, principalmente, o uso e apropriação dos testemunhos dos personagens sociais. Esses testemunhos são apresentados de forma tradicional, em planos médios. Não há uma grande inovação estética no trato com as imagens. Quanto às demais vozes articuladas, há muitos movimentos de câmera, a partir do uso de grua, mostrando ruas e casas do bairro, de maneira a dar uma visão ampla sobre o local.

A estética e modos de apropriação dos testemunhos nesse filme são operados de forma a prolongar o tempo dos depoimentos e ele se utiliza da estética do detalhe ao transcrever a fala final de cada testemunho das vozes institucionalizadas. Essa transcrição separa a narrativa em três blocos, sendo que o quarto bloco não usa a descrição para o detalhe, mas sim, o movimento de zoom das lentes da câmera. Essa transcrição se torna importante na narrativa na medida em que a fala transcrita sempre possui um caráter ideológico muito forte, referindo-se a uma Santa Maria que parece não olhar e refletir sobre seu passado. Esse aspecto é um exemplo de como a estética do detalhe opera neste documentário a fim de ressaltar e definir a enunciação na narrativa representada pelo documentarista, que se faz presente a partir dessa operação de detalhamento do que ele considera ser necessário reforçar na fala dos personagens como síntese dos blocos narrativos. 
Outro aspecto que se destaca é que os primeiros três blocos do documentário priorizam os testemunhos de personagens sociais que falam a partir de um determinado campo de saber, como é o caso do historiador Ênio Grigio, da diretora técnica do Museu Treze de Maio, Giane Vargas Escobar, e do arquiteto Nabor Silva Ribeiro. Apenas o último bloco traz testemunhos de moradores, de pessoas que vivenciaram as histórias narradas.

Mesmo dividido em quatro blocos, cada um abordando um eixo temático diferente, mas com relação entre si, a estrutura narrativa do documentário apoia-se nos testemunhos dos personagens sociais como provas de uma imagem do passado de Santa Maria, fazendo jus, mais uma vez, à estética do fragmento, que constrói a narrativa a partir de recortes de entrevistas para formar um novo sistema.

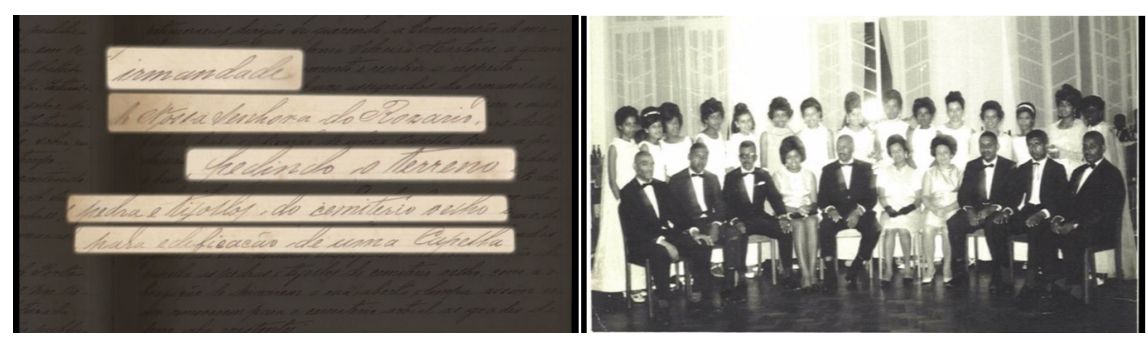

À esquerda, exemplo de animação de documentos. À direita, uma das fotografias antigas do Clube Treze de Maio, clube da elite negra do bairro.

Fonte: Qu4tro Mistérios do Rosário. TV OVO, 2012.

Esteticamente, os principais temas do filme, que são o negro e a religião, são demarcados por três elementos: o uso de animações de ilustrações, a trilha sonora puxada por um berimbau, característico da cultura afro, e a transcrição da fala final das vozes institucionalizadas.

Entre tantas formas de abordagens possíveis, a TV OVO escolheu abordar principalmente a questão da negritude, uma história que não é muito contada na cidade, e a relação dessa história com a religião, já que é a Irmandade do Rosário, situada no bairro, que constrói uma igreja somente para negros. Assim, temos imagens pontuais que demonstram isso, como as ilustrações animadas de portugueses cristianizando os escravos e de um escravo ajoelhado, com os pulsos acorrentados e um rosário envolto em suas mãos. 


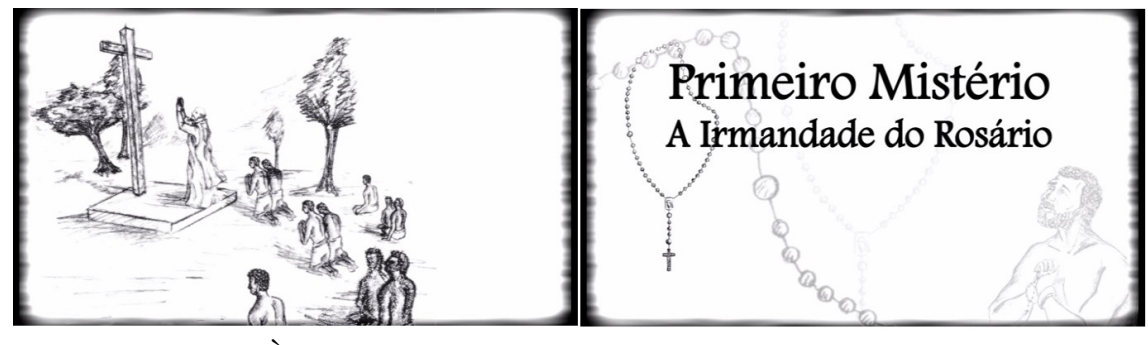

À esquerda, jesuítas cristianizam os escravos.

À direita, exemplo do início de cada bloco da narrativa.

Fonte: Qu4tro Mistérios do Rosário. TV OVO, 2012.

Além da questão negra e religiosa, no terceiro bloco aborda-se a delimitação geográfica do bairro que possui um traçado radial desde 1918, diferenciando-se do ponto de vista do mapa oficial da cidade, que entende o bairro com delimitações mais abrangentes. Mais uma vez, o bairro é representado como um local esquecido e que começa a chamar atenção no final dos anos 2000, a partir do estabelecimento de uma instituição de ensino superior na região, o Centro Universitário Franciscano (Unifra). A fala do personagem social, o arquiteto, é sustentada por inserts com animação do mapa do bairro e com registros in loco das ruas e edificações do Rosário. Elementos que, articulados, cumprem o papel de comprovar e de ilustrar o ponto de vista do depoente que, por sua vez, é assumido pelo filme.

O quarto bloco, que trata sobre a comunidade, os testemunhos dos moradores são apropriados de forma a complementar e comprovar o que foi mencionado pelas vozes institucionais, como se quem estuda o passado tem mais credibilidade para falar a respeito do que quem o viveu. E, ao contrário dos blocos anteriores, este bloco não termina com a transcrição de uma citação final. O filme se encerra com outro artifício. Toda a significação está presente no zoom que é realizado quando Maria Aparecida da Silva do Nascimento, uma das primeiras moradoras da rua São Francisco, relembra os bailes do Clube Treze de Maio, o qual ela chama de "Clube do Morenos" e que seus avós ajudaram a fundar. Ela recorda o preconceito étnico de Santa Maria e as mudanças ocorridas no bairro.

No final da fala, Maria Aparecida se emociona ao lembrar-se da mãe. Embora não haja a transcrição de um trecho da fala da personagem, como nos blocos anteriores, a estética do detalhe se revela quando a câmera faz um zoom, reenquadrando a cena, fechando o quadro no rosto da personagem social para mostrar a lágrima que deveria cair. A fala termina e segue o silêncio de Maria Aparecida no quadro. Neste mesmo momento, reinicia-se a trilha do docu- 
mentário, ao som do berimbau. A imagem vai para uma tela preta por alguns instantes.

A partir da análise deste simples dispositivo que dá um novo reenquadramento do plano, com o apoio da trilha, percebemos toda a significação do documentário, que se encerra na questão do passado escravista da cidade. Aqui se revela a presença do diretor e do diretor de fotografia na tomada de forma intencional, que quer chamar a atenção para o fato de que estamos diante de um bairro de negros que, assim como a igreja construída para e pelos negros, é usurpado pela cidade que prefere apagar os rastros dessa história, deixando-a cair no esquecimento.

A emoção de Maria Aparecida é apropriada pelo documentário para contar este outro lado da história. Interessante pensar que esse testemunho foi escolhido para aparecer no final do filme e é o único que apresenta uma mudança de enquadramento. Podemos dizer que é esse sentimento de pertencimento que interessa à TV OVO, é ele que traduz o que a TV OVO entende como memória do bairro Rosário, como história da cidade.

O documentário assume o seu enquadramento de memória ao trabalhar com as transcrições da última frase dos testemunhos de personagens sociais ao final de cada bloco e com o reenquadramento operado na emoção de Maria Aparecida. Mas ele também diz que há muitas outras histórias a serem contadas sobre o bairro quando ao final surge o letreiro que explicita que "[...]no bairro do Rosário existem muitos mistérios, histórias e causos. Aqui ficam só quatro[...]" (Qu4tro Mistérios do Rosário, 2012). Trata-se do ponto de vista sobre as lembranças do lugar, do "lugar de memória" que a TV OVO lança para o bairro Nossa Senhora do Rosário.

O documentário Trilhos do Itararé (Marcos Borba, 2012) registra a história do bairro Itararé que, vizinho à Estação Férrea, era tido como o bairro ferroviário da cidade. A narrativa gira em torno dos anos de apogeu do local, da sua constituição em função da malha ferroviária e da sua decadência após a desativação do trem de passageiros. Os destaques, para além do patrimônio imaterial, simbólico, ganham forma no Clube Ferroviário 21 de Abril, que representava o status social de quem trabalhava na ferrovia, e no Monumento ao Ferroviário, que fica no alto de um morro e carrega o legado de formação do bairro, de onde se tem uma vista panorâmica do Itararé.

A estética do filme está bastante voltada para uma narrativa fragmentada. ${ }^{6}$ Isso porque a história é contada a partir do testemunho de quatro personagens sociais, cujas falas recortadas são justapostas formando um novo todo, com-

6. Essa estética também é observada nos documentários $1^{a}$ Quadra e Avenida Progresso que não entraram na análise deste artigo e fazem parte do mesmo projeto. 
pondo uma nova narrativa histórica. E, diferente do Qu4tro Mistérios do Rosário, o Trilhos do Itararé, além das vozes articuladas com algumas fotografias antigas, mapas animados, letreiros, utiliza-se muito de imagens registradas in loco na época da produção do filme e do som do trem percorrendo os trilhos, o que se transforma numa marca sonora importante na construção da narrativa deste documentário.

O filme apresenta uma estrutura menos elaborada que o Qu4tro Mistérios do Rosário. Os testemunhos dos personagens sociais também são registrados em planos médios. Há alguns planos abertos do bairro, sendo que o principal deles apresenta o local em um movimento de panorâmica realizado no Monumento aos Ferroviários, e há muitos planos conjuntos e gerais feitos na Gare da Estação Férrea, como ênfase para os trilhos do trem. Apenas um efeito de fastmotion (aceleração da imagem), que é utilizado em uma das sequências que analisaremos abaixo, destoa do restante da linguagem empregada na narrativa.

A história do filme é conduzida por dois personagens eleitos como protagonistas: um é Amilton Santos, pertencente à família de ferroviários, que, como seu pai, também trabalhou na rede ferroviária; o outro é o trem de carga e o seu som, que ainda hoje passam por Santa Maria.

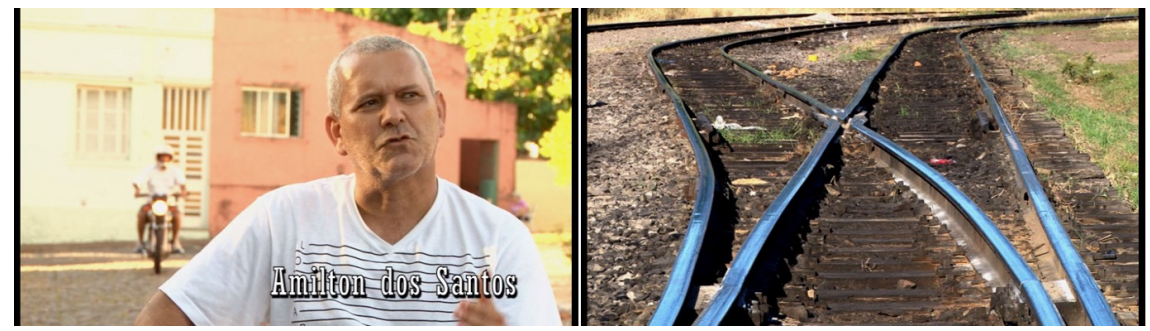

À esquerda, o personagem social e protagonista Amilton Santos. À direita, um dos planos que anunciam o trem como o outro protagonista da narrativa.

Fonte: Trilhos do Itararé. TV OVO, 2012.

O desenho do som é bastante trabalhado no Trilhos do Itararé em relação ao documentário anterior. Ele assume um papel importante na construção de sentidos na narrativa. Isso é perceptível durante a fala de Amilton Santos, que conduz a história a partir da narração do seu testemunho. Enquanto ele fala, são utilizadas muitas cenas atuais do bairro, da época de produção do filme, com o áudio ambiente no qual se sobressai o canto dos passarinhos. As cenas também são acompanhadas de uma trilha sonora em que o instrumento de destaque é uma gaita de fole. Ainda, no desenho de som, percebemos, bem baixinho, o som do trem que percorre os trilhos. Esse desenho de som faz com 
que a ideia da nostalgia se mantenha durante todo o filme. Fala-se de um trem que já passou, fisicamente, mas que continua a passar no imaginário social do bairro.

Os depoimentos dos demais são justapostos ao de Amilton. Mas as falas são como que um complemento à narrativa de Amilton. Junto a elas, por vezes, é possível ouvir o som do trem, como se ele estivesse a passar por ali justamente no instante de determinada fala.

Já os letreiros que compõem a narrativa sempre são anunciados com a presença do trem de carga e explicitam um tom de nostalgia. Uma cena que reforça esse sentido trabalha com fastmotion. O trem, num plano contraplongée, se aproxima em grande velocidade e, ao passar por cima da câmera, o movimento dos vagões volta ao seu tempo normal. Na tela surge um letreiro que encerra toda a significação do documentário: “[...] é uma nostalgia do tempo do trem que paira no ar. Mas o orgulho de ser morador do Itararé fala mais alto quando o presente vai moldando um futuro que preserva a memória dessa comunidade construída na força do trem" (Trilhos do Itararé, 2012). A imagem do trem mais uma vez é acelerada até ele sair de quadro. Esse plano reflete a relação das lembranças da ferrovia e o tempo que passou rápido e deixou profundas marcas na comunidade do seu entorno.

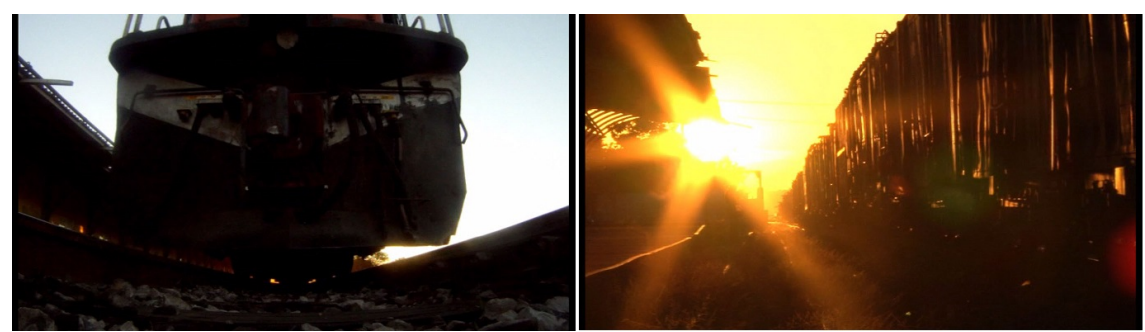

À esquerda, cena mencionada acima, com fastmotion. À direita, a cena final do documentário, mencionada no texto a seguir.

Fonte: Trilhos do Itararé. TV OVO, 2012.

Na última sequência, o trem passa pela estação ao entardecer, sem parar. O som do seu andar está mais alto. A cena termina com o trem saindo de quadro e o dia anoitecendo, uma simbologia que nos remete ao movimento da história, a um passado que já se foi, mas que permanece vivo na memória daqueles sujeitos que vivem no bairro, principalmente pelo som dos vagões nos trilhos estar presente diariamente no Itararé. São os seus testemunhos que a TV OVO representa para o resto da cidade como rastros que precisam ser rememorados, de um trem que passou e deixou um peso no bairro, hoje, de 
certa forma, esquecido pelas políticas públicas e pela própria memória santamariense. Para além da nostalgia, o filme contribui para um novo projeto de memória que busca valorizar a ferrovia como patrimônio da cidade e fazer com que esse passado não caia no esquecimento, como se encontra atualmente, com relação tanto à ferrovia quanto ao bairro. Do ponto de vista do documentário da TV OVO, a partir dos testemunhos articulados, ambos pararam no tempo com a desativação do trem de passageiros. O documentário também assume a dor dos ferroviários.

\section{Santa Maria projetada: ressignificações da memória e da identidade}

Depois de apresentar nosso objeto de estudo, o eixo metodológico dessa pesquisa e a análise dos documentários, abordamos a questão levantada em nossa problematização, isto é, em que medida estas produções audiovisuais exercem uma perspectiva de comunicação contra-hegemônica, enquanto práticas comunicacionais de viés comunitário, evocando um projeto de memória e construindo uma identidade para a cidade de Santa Maria.

Ao analisarmos qual é a imagem que os filmes representam da memória de Santa Maria e que identidade eles projetam para a cidade, entendemos que os dois documentários aqui analisados abordam uma imagem-memória contrahegemônica e constroem uma identidade de projeto para a cidade.

O documentário Qu4tro Mistérios do Rosário aborda uma imagem-memória contra-hegemônica na medida em que apresenta a história do bairro Rosário que foi, de certa forma, esquecida pela memória-história de Santa Maria. Ele traz um ponto de vista diferenciado ao sustentar sua retórica a partir dos testemunhos de personagens sociais negros e menos favorecidos economicamente, um discurso que tem origem em uma etnia e em uma classe social excluída do trabalho de construção da identidade santa-mariense.

Ainda, no discurso do filme, notamos uma informação que não é apresentada pela historiografia oficial da cidade: a briga pelo litígio da Igreja do Rosário entre a Irmandade e o Padre Caetano Pagliuca, em que o padre toma a posse da igreja. Tanto o livro de João Belém (1933) quanto o artigo de João Rodolpho Amaral Flores (2010) falam do padre enquanto um homem de grandes feitos e que retomou o catolicismo na cidade, mas não mencionam esta questão, sequer falam da existência de uma população negra santa-mariense. Apenas Romeu Beltrão (1958) traz essa informação, mas de forma bem simplista, somente como citação do fato.

Outro aspecto apresentado pelo documentário é o questionamento em relação às políticas de preservação do patrimônio da cidade, em que o Bairro Nossa Senhora do Rosário não é contemplado pelo plano diretor de Santa Ma- 
ria. E assim como nos demais documentários, a ferrovia é lembrada como fator importante no desenvolvimento do município, mas sob outro olhar - o olhar daqueles que movimentavam a Maria Fumaça, os negros que trabalhavam na malha ferroviária.

A identidade que o Qu4tro Mistérios do Rosário constrói é uma identidade de projeto, ao passo que busca um sentido de transformação social. Uma identidade que produz sujeitos de sua própria história, representados pelo documentário ao tratar de temas como a criação do Clube Treze de Maio e da Igreja do Rosário, espaços que a princípio eram voltados para a negritude. O documentário conta a história da formação da comunidade negra em Santa Maria e da luta para que a cidade reconheça esse passado.

O documentário Trilhos do Itararé, ao se voltar para o passado ferroviário da cidade, traz uma imagem-memória contra-hegemônica, já que busca tirar do silêncio uma memória coletiva de Santa Maria. O discurso opera a partir do saudosismo da ferrovia, mas não deixa de apresentar as feridas abertas que o fim do trem de passageiros deixou. O filme também fala do abandono que o bairro Itararé tem sofrido no que se refere às políticas públicas da prefeitura e, também, à própria memória-história da cidade.

A imagem-memória deste documentário é contra-hegemônica e a identidade que ele representa é a de projeto. Essa identidade se apresenta na medida em que o Trilhos do Itararé mostra que o sentimento de pertencimento, o orgulho e a memória da ferrovia resistiram, mesmo que o final da história não tenha sido tão feliz. Ela se configura ainda pelo documentário se somar com o movimento historiográfico dos últimos 30 anos, que se volta para Santa Maria como uma "Cidade Ferroviária" e não somente "Cidade Cultura". É uma identidade que se movimenta em vias de legitimação, pois, como lembra Castells (2006), nenhuma identidade compõe uma essência, elas são dinâmicas, permeadas por transformações e sempre por estruturas de poder.

\section{Considerações finais}

A ressignificação da memória e da identidade da cidade começa no momento em que a TV OVO elege determinados lugares em detrimento de outros para serem temas de seus documentários. Hegemônica ou não, a representação dessas eleições sempre tem a carga da ressignificação, pois atualizam memórias e trazem, em maior ou menor grau, as impressões do grupo que registra essa história. Contudo, podemos dizer que essa ressignificação adquire maior peso quando tem o tom da contra-hegemonia, pois apresenta novas significações que não estão contempladas no âmbito da historiografia oficial. 
O passado de Santa Maria é atualizado na relação entre tempo presente e tempo passado que se estabelece na abordagem dos temas nos documentários. Aliás, falar do ontem no hoje é sempre uma atualização, pois esse rememorar sempre carregará traços do agora. Percebemos essa atualização nos documentários na medida em que trazem bem marcado o hoje, resultado do ontem, e que, para além dessa relação, desenham traços da memória-história que foram apagados com o tempo.

A memória, a qual chamamos aqui de imagem-memória, e a identidade que os documentários da TV OVO projetam para Santa Maria são a de uma imagem-memória que se orienta pelas fronteiras da contra-hegemonia, mas que não necessariamente representa uma identidade de resistência. A construção da identidade apresentada pelos documentários está muito mais para uma identidade de projeto, isto é, uma identidade que saiu das linhas da resistência e que agora, num movimento de reconhecimento e de autoafirmação, pode vir a legitimar-se. Por outro lado, podem permanecer nas linhas da resistência se os documentários não circularem e se a cidade não se apropriar dessa história pouco contada.

A partir desses pressupostos, identificamos os documentários como um projeto de memória, um "lugar de memória" para Santa Maria que traduz os anseios culturais de uma mídia comunitária preocupada com a preservação e com o registro da memória da cidade em que ela nasceu, mas que também tem certa dependência de políticas públicas, como editais e leis de incentivo, para realizar suas ações no campo do audiovisual. Este aspecto tem permeado a comunicação comunitária contemporânea, tanto que podemos vê-lo refletido no projeto da TV OVO. Ao submeter-se em determinados editais, há constrangimentos de estruturas de poder, porque sempre há memórias que são priorizadas em detrimento de outras. Nem sempre as memórias de grupos periféricos ou comunitários estão entre as preteridas. Por outro lado, recursos destinados para iniciativas por meio de políticas públicas voltadas para a cultura proporcionam intervenções sociais que poderiam não ocorrer caso não houvesse essa possibilidade de financiamento.

Produções audiovisuais como as da TV OVO tornam-se uma importante ferramenta para debater o patrimônio cultural de uma cidade, a fim de fomentar a sua preservação e a educação. Afinal, compreender o patrimônio e a sua formação permite a uma comunidade se reconhecer e conhecer o seu lugar, criar laços de pertencimento, respeitar as diferenças e transferir conhecimentos. Talvez este aspecto justifique o porquê de trabalhar com tanto enfoque no modo de representação expositivo. Ao querer dar espaço para a comunidade e contar uma história que seja compreensível para diferentes graus de escola- 
ridade e classes sociais, o modo expositivo parece contribuir para um entendimento mais rápido e por se aproximar da linguagem televisiva, que costuma ter maior alcance na sociedade.

Esse tipo de produção também nos mostra que a comunicação comunitária subsiste. Em todos os períodos da história, em qualquer época, sempre haverá constrangimentos, estruturas de poder, sejam elas políticas, econômicas, ideológicas, que irão enquadrar as formas de atuação, por mais democrático que seja o regime político. São resultado de processos, em que a comunicação sempre se dará a partir de tensões e conflitos. Contudo, iniciativas como a da TV OVO, que conseguem sobrepor barreiras e manter um olhar diferenciado da grande mídia, têm um papel importante de intervenção social. Neste caso, trazer um reolhar, no sentido de voltar-se mais uma vez ao passado, para preservar o que ainda resta e registrá-lo para futuras gerações, torna-se importante na medida em que propõem reflexões acerca de presente, passado e futuro. Afinal, toda sociedade precisa de uma memória para fundamentar sua identidade. Uma sociedade sem identidade é uma sociedade que flutua no limbo da existência, que não sabe quem é e nem para onde vai.

\section{Referências Bibliográficas}

Balogh, A.M. \& Droguett, J. (2008). Diálogos de antropofagia audiovisual. Comunicação \& Inovação, 9(16-1): 42-49. São Caetano do Sul.

Belém, J. (2000). História do Município de Santa Maria - 1793-1933, 3ª ed. Santa Maria: Editora da UFSM.

Beltrão, R. (1979). Cronologia histórica de Santa Maria e do extinto município de São Martinho (1787 - 1930). Santa Maria: Pallotti.

Calabrese, O. (1987). A idade neobarroca. Tradução de C. Carvalho \& A. Morão, São Paulo: Martins Fontes.

Castells, M. (2006). O poder da identidade. São Paulo: Paz e Terra.

Flores, J.R.A. (2010). Patrimônio, memória e historiografia. In B.T. Weber \& J. Ribeiro (Org.), Nova História de Santa Maria. Contribuições recentes (pp. 17-42). Santa Maria: [s.n.].

Gramsci, A. (1984). Cuadernos de la cárcel, Tomo III. Traducción de A.M. Palos. Edición crítica del Instituto Gramsci a cargo de Valentino Gerratana. México: Ed. Era.

Nichols, B. (2005). Introdução do documentário. Campinas, SP: Papirus.

Nora, P. (1993). Entre memória e história. A problemática dos lugares. Revista Projeto História, (10): 7-28. São Paulo: PUC. 


\section{Filmografia}

Qu4tro Mistérios do Rosário (2012), de Marcos Borba.

Trilhos do Itararé (2012), de Marcos Borba. 